Utah State University

DigitalCommons@USU

$1-1-2014$

\title{
Derivation and Use of Simple Relationships Between Aerodynamic and Optical Particle Measurements
}

Kori D. Moore

Randal S. Martin

William J. Bradford

Christian C. Marchant

Derek S. Jones

Michael D. Wojcik

See next page for additional authors

Follow this and additional works at: https://digitalcommons.usu.edu/sdl_pubs

\section{Recommended Citation}

Moore, Kori D.; Martin, Randal S.; Bradford, William J.; Marchant, Christian C.; Jones, Derek S.; Wojcik, Michael D.; Pfeiffer, Richard L.; Prueger, John H.; and Hatfield, Jerry L., "Derivation and Use of Simple Relationships Between Aerodynamic and Optical Particle Measurements" (2014). Space Dynamics Lab Publications. Paper 161.

https://digitalcommons.usu.edu/sdl_pubs/161

This Article is brought to you for free and open access by the Space Dynamics Lab at DigitalCommons@USU. It has been accepted for inclusion in Space Dynamics Lab Publications by an authorized administrator of DigitalCommons@USU. For more information, please contact digitalcommons@usu.edu.

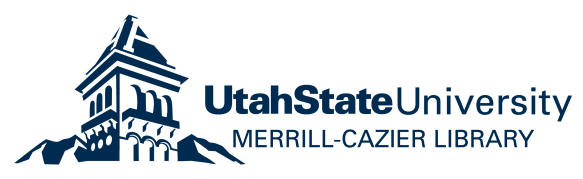




\section{Authors}

Kori D. Moore, Randal S. Martin, William J. Bradford, Christian C. Marchant, Derek S. Jones, Michael D. Wojcik, Richard L. Pfeiffer, John H. Prueger, and Jerry L. Hatfield 


\title{
Derivation and Use of Simple Relationships between Aerodynamic and Optical Particle Measurements
}

\author{
Kori D. Moore ${ }^{1}$; Randal S. Martin²; William J. Bradford ${ }^{3}$; Christian C. Marchant ${ }^{4}$; Derek S. Jones ${ }^{5}$; \\ Michael D. Wojcik ${ }^{6}$; Richard L. Pfeiffer ${ }^{7}$; John H. Prueger ${ }^{8}$; and Jerry L. Hatfield ${ }^{9}$
}

\begin{abstract}
A simple relationship, referred to as a mass conversion factor (MCF), is presented to convert optically based particle measurements to mass concentration. It is calculated from filter-based samples and optical particle counter (OPC) data on a daily or sample period basis. The MCF allows for greater temporal and spatial mass concentration information than typical filter-based measurements. Results of MCF calculations from several field studies are summarized. Pairwise comparisons from a collocated study with multiple OPCs and mass samplers suggest the minimum variability of the MCF is 5-10\%. The variability of the MCF within a sample period during a field study with distributed samplers averaged 17-21\%. In addition, the precision of the Airmetrics MiniVol Portable Air Sampler for particulate matter (PM) was typically $<10 \%$. Comparisons with federal reference method (FRM) samplers showed that MiniVols yield $\mathrm{PM}_{2.5}$ concentrations essentially equivalent to FRMs with slightly greater deviations from the FRM for PM $_{10}$ under tested ambient conditions. DOI: 10.1061/(ASCE) EE.1943-7870.0000893. (C) 2014 American Society of Civil Engineers.
\end{abstract}

Author keywords: Air pollution; Particles; Monitoring; Instrumentation; Calibration; Remote sensing.

\section{Introduction}

Many different properties can be used to describe a single particle. These include shape, chemical speciation, density, index of

${ }^{1}$ Environmental Engineer, Space Dynamics Laboratory, Utah State Univ. Research Foundation, 1695 North Research Park Way, North Logan, UT 84341; and Graduate Student, Dept. of Civil and Environmental Engineering, Utah State Univ., 4110 Old Main Hill, Logan, UT 84322 (corresponding author). E-mail: kori.moore@sdl.usu.edu

${ }^{2}$ Associate Research Professor, Dept. of Civil and Environmental Engineering, Utah State Univ., 4110 Old Main Hill, Logan, UT 84322.

${ }^{3}$ Applications Engineer, Campbell Scientific, 815 West 1800 North, Logan, UT 84321; formerly, Space Dynamics Laboratory, Utah State Univ. Research Foundation, 1695 North Research Park Way, North Logan, UT 84341.

${ }^{4}$ Data Analyst, National Geospatial-Intelligence Agency, 7500 Geoint Dr., Springfield, VA 22150; formerly, Space Dynamics Laboratory, Utah State Univ. Research Foundation, 1695 North Research Park Way, North Logan, UT 84341.

${ }^{5}$ Applications Engineer, Campbell Scientific, 815 West 1800 North, Logan, UT 84321; formerly, Space Dynamics Laboratory, Utah State Univ. Research Foundation, 1695 North Research Park Way, North Logan, UT 84341.

${ }^{6}$ Senior Scientist, Space Dynamics Laboratory, Utah State Univ. Research Foundation, 1695 North Research Park Way, North Logan, UT 84341

${ }^{7}$ Chemist, National Laboratory for Agriculture and the Environment, Agricultural Research Service, U.S. Dept. of Agriculture, 2110 University Blvd., Ames, IA 50011.

${ }^{8}$ Research Soil Scientist, National Laboratory for Agriculture and the Environment, Agricultural Research Service, U.S. Dept. of Agriculture, 2110 University Blvd., Ames, IA 50011.

${ }^{9}$ Laboratory Director, National Laboratory for Agriculture and the Environment, Agricultural Research Service, U.S. Dept. of Agriculture, 2110 University Blvd., Ames, IA 50011.

Note. This manuscript was submitted on February 21, 2014; approved on July 30, 2014; published online on October 14, 2014. Discussion period open until March 14, 2015; separate discussions must be submitted for individual papers. This paper is part of the Journal of Environmental Engineering, (C) ASCE, ISSN 0733-9372/04014078(9)/\$25.00. refraction, aerodynamic diameter, optical diameter, and so on. Numerous measurement techniques have been developed to quantify various properties, although most are capable of measuring only one or two properties. Comparisons between simultaneous measurements of an aerosol mixture made using different techniques may provide valuable information about relationships between the measurement methodologies and the measured properties, as well as additional information not measured.

Estimating specific particle properties even from a combination of measurement techniques may be challenging both theoretically and in practice. For example, Schmid et al. (2007) provides a detailed explanation of mathematical relationships between density, shape, effective density, and various equivalent diameters for spherical and nonspherical particles. Deriving a property from such methods requires significant investment in equipment, as well as knowledge or assumptions of other pertinent particle properties. However, comparisons between two or more measurement techniques may be made in order to derive an empirical relationship that incorporates all applicable properties into a more simple expression. While this method does not provide insight into the values of specific properties, it can be very useful in calibrating the output of a sensor to provide information not directly measured, such as the calibration of an optical particle counter (OPC) to provide particulate matter (PM) mass concentration. A significant advantage of an OPC over typical filter-based mass samplers is that the OPC can provide a much more temporally resolved dataset and may yield valuable information about changes in concentration.

Binnig et al. (2007) describes the calibration of an OPC to yield concentrations of PM with an aerodynamic diameter $\left(d_{a}\right) \leq$ $2.5 \mu \mathrm{m}\left(\mathrm{PM}_{2.5}\right)$ for a well-defined aerosol utilizing known particle density and assuming uniform composition across the size range. This procedure, however, should not be applied in situations with significant fractions of particles that are not well-defined, as is often the case in ambient measurements. Instead, researchers tend to rely on historical data to develop these empirical relationships for converting optical measurements to PM mass concentrations (Grimm and Eatough 2009). Several commercially available ambient PM 
monitors currently utilize mass conversion relationships based on historical data to report PM concentrations from optical systems, such as the Aerosol Spectrometer series by GRIMM Technologies (Ainring, Germany), the TSI DustTrak series (Shoreview, Minnesota), and the Palas Fidas System (Karlsruhe, Germany).

The accuracy of PM concentrations, calculated from optical data and converted using relationships based on historical data, is strongly influenced by how closely the properties of the monitored aerosol match the properties of the historical dataset. For instance, errors in PM estimates at a clean background site, rural site, or a site heavily impacted by a single source could be significant if the employed PM calibration was created from measurements in an urban area, all of which have different aerosol sources and thus optical properties. Estimating this relationship based on measurements of the aerosol of interest through an in situ calibration, referred to by the writers as the mass conversion factor (MCF), can decrease the error due to dissimilar aerosols. This method may also be used to provide a sample period PM calibration for instruments that do not have a historical dataset. Zavyalov et al. (2009) touched very briefly on how the MCF is calculated and potential uses. In this paper more details are provided on calculating the MCF, data collected during field measurements is presented that have been used to calculate MCFs, and examples are given of how the MCFs have been used to estimate PM mass concentrations from optical sensors on finer timescales than filter-based measurements. In addition, results of multiple comparison studies between the filter-based PM samplers used in these studies to federal reference method (FRM) samplers are presented.

\section{Methodology}

\section{Instrumentation and Analysis}

The PM mass concentration data were collected using filter-based MiniVol portable air samplers from Airmetrics (Eugene, Oregon). These are portable, battery-operated instruments with programmable sample times. Air is pulled into the sample head at a nominal flow rate of $5.0 \mathrm{~L} \mathrm{~min}^{-1}$ where size separation occurs based on particle inertia through the use of a removable impactor plate assembly. This inertial particle separation method is the same principle as that used in FRM samplers for PM with $d_{a} \leq$ $10 \mu \mathrm{m}\left(\mathrm{PM}_{10}\right)$ and $\mathrm{PM}_{2.5}$, although the design is different and the collection efficiency curve of the MiniVol assembly is not as steep as that of the FRM samplers (Hill et al. 1999). The MiniVol can sample $\mathrm{PM}_{10}, \mathrm{PM}_{2.5}$, or PM with $d_{a} \leq 1 \mu \mathrm{m}\left(\mathrm{PM}_{1}\right)$, depending on the impactor assembly used; total suspended particulate (TSP) matter may be collected if the impactor assembly is not used. Impaction plates were coated with a thin layer of high vacuum silicone grease to prevent particles removed from the airstream from being reentrained in the sample flow. A filter holder is located downstream of the size separator to collect particles remaining in the airstream.

Sample flow is not actively maintained at $5.0 \mathrm{~L} \mathrm{~min}^{-1}$ by the MiniVol. Instead, it is set using a calibrated rotameter before each run and verified during sample retrieval. Flow calibrations were conducted yearly and prior to deployment for each instrument used. The calibration equations and estimated sample period average pressure and ambient temperature $\left(T_{\mathrm{amb}}\right)$ were used to calculate the sample period specific rotameter settings necessary to achieve a sample flow of $5.0 \mathrm{~L} \mathrm{~min}^{-1}$. Occasional sampling or handling irregularities occurred with MiniVol samples, all of which were noted. Any sample with a noted issue was excluded from further calculations.
Teflon filters $47 \mathrm{~mm}$ in diameter were used to collect all samples herein reported. Filters were preconditioned according to the protocols outlined in Title 40, Part 50, Appendix J of the U.S. Code of Federal Regulations (i.e., 40 CFR 50 Appendix J). Final average filter weights for both pretest and posttest were calculated from three stable weights within $\pm 5 \mu \mathrm{g}$ determined using a microbalance, Type MT5 (Mettler-Toledo, Columbus, Ohio). Calculated concentration values represent a sample period average. Balance accuracy was verified every 10 filter measurements using a 1.000-mg calibration weight.

Aerosol Profilers, Model No. 9722 (Met One Instruments, Grants Pass, Oregon) were used to measure the optical diameter $\left(d_{\mathrm{op}}\right)$ of individual particles. These OPCs measure the amount of light scattered by a particle and compare that quantity to light scattered by calibration particles of various sizes to determine the particle $d_{\mathrm{op}}$. Measured $d_{\mathrm{op}}$ are grouped into eight bins with the following size ranges: (1) $0.3-0.5 \mu \mathrm{m}$, (2) $0.5-0.6 \mu \mathrm{m}$, (3) $0.6-1.0 \mu \mathrm{m}$, (4) $1.0-2.0 \mu \mathrm{m}$, (5) $2.0-2.5 \mu \mathrm{m}$, (6) $2.5-5.0 \mu \mathrm{m}$, (7) $5.0-10.0 \mu \mathrm{m}$, and (8) $>10.0 \mu \mathrm{m}$. The OPC produces total particle counts per size bin over the sample period of duration $t$, ranging from 2 to $60 \mathrm{~s}$. The PM mass concentration calibrations based on historical data have not been developed for these OPCs. The OPC flow measurements, usually made before and after experiments using a soap bubble displacement system (Gilian Gilibrator2 Calibration System, Sensidyne, Clearwater, Florida), reported that average flow rates $(q)$ ranged from $0.8-1.2 \mathrm{~L} \mathrm{~min}^{-1}$ between OPCs but that the $q$ for a given OPC was very stable. Sampled aerosol was not preconditioned to control temperature or relative humidity $(\mathrm{RH})$ in measurements reported in this paper as they were made in dry climates. However, preconditioning is suggested as high $\mathrm{RH}$ may have substantial effects on particle properties and measurements, particularly for hygroscopic particles.

For a specific OPC $(j)$, number concentration $\left(N_{i j}\right)$ per bin $(i)$ is a function of raw particle counts $\left(p_{i j}\right)$, the measured average flow rate $\left(q_{j}\right)$, and the sample time $(t)$

$$
N_{i j}=\frac{p_{i j}}{q_{j} t}
$$

The units for $N$ are no. $\mathrm{cm}^{-3}, p$ is number, $q$ are $\mathrm{cm}^{3} \mathrm{~min}^{-1}$, and $t$ is min.

Intercalibration of OPC particle counts was performed in postanalysis to ensure comparability between deployment sites. The intercalibration equations, referred to by the authors as counting correction factors (CCFs), were calculated based on data collected either as a collocated group before or after an experiment or, if a collocated dataset did not exist, from multiple periods over the deployment during which the source under study was not active and OPCs were measuring a consistent, uniform background aerosol. As instrument response for each upper bin limit in each OPC must be factory calibrated individually, so too the CCFs must be calculated for each bin of each OPC. A $\mathrm{CCF}_{i j}$ is estimated through comparison of the average particle number concentration $\left(\check{N}_{i j}\right)$ over the identified period with the average particle number concentration across all OPCs $\left(\check{N}_{i}\right)$. The CCFs were applied to all $N_{i j}$ prior to further analysis.

Both scalar and linear function $(y=m x+b)$ CCFs greatly decrease interinstrument variability. As an example, the variability between $\check{N}_{i j}$ prior to CCF application to a collocated dataset was $18.0 \%$, calculated as the relative standard deviation (RSD). Application of scalar $\mathrm{CCF}_{i j}$ values reduced the RSD to $6.8 \%$ and application of linear function CCFs yielded a RSD of $6.5 \%$. Other types of $\mathrm{CCF}$ equations may be used as deemed appropriate.

The volume concentration $(V)$ of sampled particles based on $N$ may be calculated based on the following simplifying assumptions: 
(1) the particles are spheres, and (2) the maximum measured $d_{\text {op }}$ is $20 \mu \mathrm{m}$. The assumption of a maximum measured $d_{\text {op }}$ provides an upper bound for the largest-sized channel. The geometric mean $d_{\mathrm{op}}$ per bin $\left(\mathrm{GMD}_{i}\right)$ was selected as the representative diameter of the particles in a given bin $i$ with the assumption of a log-normal distribution of particle counts. The cumulative $V\left(V_{k}\right)$ up to a particle diameter $k\left(d_{k}\right)$ may be calculated

$$
V_{k}=\frac{\pi}{6} \int_{0}^{d_{k}} n(d) d^{3} d d
$$

where $n(d)=$ number concentration at diameter $d$. For application to the collected OPC data, Eq. (2) is discretized and expressed in the subsequent terms that have been previously defined

$$
V_{k}=\frac{\pi}{6} \sum_{i=1}^{\mathrm{GMD}_{i} \leq d_{k}} \mathrm{GMD}_{i}^{3} N_{i}
$$

where the units are $\operatorname{GMD}_{i}(\mu \mathrm{m}) ; N_{i}\left(\right.$ no. $\left.\mathrm{cm}^{-3}\right)$; and $V_{k}\left(\mu \mathrm{m}^{3} \mathrm{~cm}^{-3}\right)$. In this case, the $V_{k}$ definition is similar to $\mathrm{PM}_{k}$ concentrations; the total volume of particles whose $d_{\mathrm{op}}$ is $\leq k=1 \mu \mathrm{m}, 2.5 \mu \mathrm{m}, 10 \mu \mathrm{m}$, and $\infty$ for TSP.

\section{Mass Conversion Factor Calculations}

The MCF is calculated from optical and aerodynamic particle measurements. The $V_{k}$ data, as calculated in Eq. (3), are averaged over the corresponding MiniVol sample time. The MCF, with units of density (grams per cubic cemtimeter), for each PM size fraction $k$ is calculated

$$
\mathrm{MCF}_{k}=\frac{\mathrm{PM}_{k}}{V_{k}}
$$

The MCF is typically averaged across sample locations. This MCF is different from the MCF described by Binnig et al. (2007), which includes particle shape factor and density, information that must be supplied by the user. However, this MCF incorporates the many properties from the particles, the environment, and the measurement techniques that influence the reported $\mathrm{PM}_{k}$ and $V_{k}$ values without requiring explicit consideration. Including these factors in the MCF may lead to significantly different values and larger variability in $\mathrm{MCF}_{k}$ across sample periods and instrumentation than other conversion factors (or mean density correction methods) report.

Properties of particles that may influence optical and aerodynamic measurements include but are not limited to chemical composition, effective density, shape, and index of refraction, which are interdependent to varying degrees. Chemical composition affects both the index of refraction and effective density. As OPC measurements are influenced by a particle's index of refraction, differences in indices of refraction between measured ambient and calibration particles may result in significant differences between a particle's physical diameter $\left(d_{p}\right)$ and $d_{\mathrm{op}}$, leading to potentially significant differences between calculated and actual $V$ and $V_{k}$. The OPC $d_{\text {op }}$ sizing calibrations were performed by the manufacturer with polystyrene latex (PSL) spheres. These calibrations were used for all sample periods. No attempts were made to calibrate the OPCs to local aerosol mixtures due to their complex and changing natures. This may result in positive or negative biases in sizing, with the degree of impact varying with ambient aerosol $d_{p}$ and chemical composition.

Particle properties also influence filter-based measurements. The MiniVol impactor assembly separates particles based on $d_{a}$, which is influenced by $d_{p}$, effective density, and shape, among other factors. Combining optical and aerodynamic measurements in calculating the MCF also combines the effects of particle properties, with varying impacts. For instance, if a particle has a $d_{a}$ larger than a MiniVol assembly cut point but a $d_{\text {op }}$ smaller than the lower bin limit of the OPC channel corresponding to the MiniVol assembly cut point, it may be included in $V_{k}$ as a smaller particle but not in $\mathrm{PM}_{k}$, leading to a smaller $\mathrm{MCF}_{k}$. The inverse situation with $d_{\mathrm{op}}$ and $d_{a}$ may also occur, resulting in a larger $\mathrm{MCF}_{k}$.

Additional complications may arise from the past and current ambient environments in which the particle(s) has (have) been suspended. For instance, $T_{\mathrm{amb}}$ may affect chemical composition as volatile and semivolatile compounds are found as both gases and particles over the typical range of $T_{\mathrm{amb}}$. Also, some compounds common in ambient particles, such as ammonium sulfate $\left[\left(\mathrm{NH}_{4}\right)_{2} \mathrm{SO}_{4}\right]$ and ammonium nitrate $\left(\mathrm{NH}_{4} \mathrm{NO}_{3}\right)$, readily absorb water at RH conditions above their deliquescence point, which varies between compounds and with $T_{\mathrm{amb}}$, and thus increase the particle size and change the chemical composition (Finlayson-Pitts and Pitts 1999). Effects of $T_{\mathrm{amb}}$ and RH will be different between optical-based and filter-based samplers and may be large, particularly for hygroscopic particles, depending on the similarity of sample period $T_{\mathrm{amb}}$ and $\mathrm{RH}$ conditions to those used in filter conditioning. The MCF envelops all of these effects without requiring their quantification.

The sampling properties of the instruments used to measure $\mathrm{PM}_{k}$ and $V_{k}$ also influence the MCF. One factor is particle aspiration effectiveness, particularly for large particles. This refers to how well particles of a given size are drawn into the system at the inlet. It is a strong function of a particle's inertia and $d_{a}$, and the inlet design. Marchant et al. (2011), based on conversations with Met One Instruments, stated that particles with $d_{a}$ larger than about $25 \mu \mathrm{m}$ are not likely to enter the OPC inlet and that the aspiration efficiency of particles down to $5 \mu \mathrm{m}$ may be affected at wind speeds greater than $\sim 3 \mathrm{~ms}^{-1}$. Baldauf et al. (2001) reported that aspiration efficiencies for MiniVols for particles with $d_{a}=10 \mu \mathrm{m}$ vary from $100 \%$ at a wind speed of $1.4 \mathrm{~ms}^{-1}$ to $\sim 70 \%$ at a wind speed of $16.7 \mathrm{~ms}^{-1}$.

One factor affecting mass measurement systems is the effectiveness of the size selection mechanism. The FRM PM 10 and $\mathrm{PM}_{2.5}$ size segregation sample heads have been designed to mimic the particle removal efficiency of the human respiratory system, with most utilizing a particle's inertia for separation if it is above the designed $d_{a}$ cut point. The removal efficiencies can be represented by an s-shaped curve with some particles smaller than the targeted cut point being removed, half the particles at the cut point being removed, and some particles larger than the cut point passing through the removal mechanism. The MiniVol impactor removal efficiency is designed to be similar to FRMs, although the slope is not as steep (Hill et al. 1999). Significant particle loading on the MiniVol impactor plate may lead to particles impacting the surface and returning to the airstream for collection on the filter. This is known as particle bounce and may result in higher $\mathrm{PM}_{k}$ being reported than is actually present. The manufacturer suggests the use of a thin grease film on the impactor plate as a preventative measure, with a cleaning and film renewal cycle based on sampling frequency and sampled concentrations. If cleaning and renewal cycles are too infrequent, particle buildup may occur and result in particle bounce (Tropp et al. 1998).

The MCF values have been calculated from data collected during six field studies conducted in the San Joaquin Valley (SJV) of California, in the Cache Valley along the border between Utah and Idaho, and on the Colorado Plateau in eastern Utah. Measurements were taken during summer and fall seasons between the years 2007 and 2012, under the meteorological and potential PM source conditions listed (Table 1). Field study average $T_{\text {amb }}$ were above $20^{\circ} \mathrm{C}$ during all but one, and average $\mathrm{RH}$ values were in the $30-40 \%$ range. Maximum RH values were between 60 and $80 \%$, and 
Table 1. Conditions during Each Field Campaign with the Mass Conversion Factor Calculated and Included in This Paper

\begin{tabular}{|c|c|c|c|c|c|c|c|c|}
\hline \multirow[b]{2}{*}{ Location } & \multirow[b]{2}{*}{$\begin{array}{l}\text { Month(s) } \\
\text { and year }\end{array}$} & \multirow[b]{2}{*}{$\begin{array}{l}\text { Sample } \\
\text { periods }\end{array}$} & \multicolumn{4}{|c|}{ Meteorological conditions ${ }^{\mathrm{a}}$} & \multirow[b]{2}{*}{ Potential PM sources } & \multirow[b]{2}{*}{ References } \\
\hline & & & & $\begin{array}{c}\text { Average } \pm \\
\text { SD }\end{array}$ & Minimum & Maximum & & \\
\hline \multirow{12}{*}{$\begin{array}{l}\text { Cache Valley, } \\
\text { UT } \\
\text { Colorado Plateau, } \\
\text { UT } \\
\text { San Joaquin Valley, } \\
\text { CA }\end{array}$} & July 2007 & 5 & $T_{\mathrm{amb}}\left({ }^{\circ} \mathrm{C}\right)$ & $25 \pm 7$ & 11 & 36 & \multirow{4}{*}{$\begin{array}{l}\text { Combustion, small industrial processes, } \\
\text { agriculture, construction, and mobile } \\
\text { Long-range transport (Malm et al. 2004), } \\
\text { windblown dust, mobile, and unpaved roads }\end{array}$} & \multirow[t]{2}{*}{ - } \\
\hline & & & RH (\%) & $40 \pm 22$ & 12 & 86 & & \\
\hline & October & 4 & $T_{\mathrm{amb}}\left({ }^{\circ} \mathrm{C}\right)$ & $9 \pm 5$ & -4 & 18 & & \multirow[t]{2}{*}{ - } \\
\hline & 2009 & & RH (\%) & $41 \pm 15$ & 17 & 71 & & \\
\hline & October & 7 & $T_{\mathrm{amb}}\left({ }^{\circ} \mathrm{C}\right)$ & $23 \pm 4$ & 14 & 30 & \multirow{4}{*}{$\begin{array}{l}\text { Samples collected around agricultural } \\
\text { operations. Other sources include } \\
\text { i.e., combustion, industrial processes, } \\
\text { construction, mobile, and others }\end{array}$} & \multirow{4}{*}{$\begin{array}{c}\text { Moore } \\
\text { et al. }(2013 \\
\quad-\end{array}$} \\
\hline & 2007 & & $\mathrm{RH}(\%)$ & $38 \pm 14$ & 17 & 79 & & \\
\hline & May and & 13 & $T_{\mathrm{amb}}\left({ }^{\circ} \mathrm{C}\right)$ & $30 \pm 4$ & 18 & 37 & & \\
\hline & June 2008 & & RH (\%) & $28 \pm 10$ & 11 & 64 & & \\
\hline & June 2008 & 7 & $T_{\mathrm{amb}}\left({ }^{\circ} \mathrm{C}\right)$ & $28 \pm 7$ & 15 & 39 & (Held et al. 2004) & \multirow{2}{*}{$\begin{array}{l}\text { Marchant } \\
\text { et al. (2011) }\end{array}$} \\
\hline & & & RH (\%) & $39 \pm 17$ & 13 & 77 & & \\
\hline & August & 5 & $T_{\mathrm{amb}}\left({ }^{\circ} \mathrm{C}\right)$ & $28 \pm 6$ & 13 & 37 & & - \\
\hline & 2012 & & RH (\%) & $39 \pm 18$ & 20 & 85 & & \\
\hline
\end{tabular}

${ }^{\mathrm{a}}$ Meteorological values are those recorded during sample periods only.

occurred for short periods of time in early morning when $T_{\mathrm{amb}}$ was lowest. Typical point sensor deployment on these field studies consisted of collocating an OPC with one to four MiniVol samplers. Sampler inlets were arranged at approximately the same elevation above ground level (AGL) and within a circle of radius $\leq 1.5 \mathrm{~m}$ with a minimum separation distance between inlets of $0.3 \mathrm{~m}$ to prevent interference. Samples were collected between 2 and $10 \mathrm{~m}$ AGL. MiniVol sample periods ranged from 1 to $24 \mathrm{~h}$, depending on sampling objectives, while OPCs recorded data continuously in 20-s intervals. Proper maintenance of the MiniVol impactor plate surface was a priority in each deployment.

\section{MiniVol Accuracy and Precision Tests}

Several collocated ambient tests were conducted in which multiple MiniVols and one or two FRM samplers were deployed to determine the precision and accuracy of the MiniVols. The FRM instruments used were Anderson regulated air sampler (RAS) units operated by the writers for $\mathrm{PM}_{10}$, a Partisol Plus Model 2025 sequential air sampler operated by the State of Utah Division of Air Quality (UDAQ) for $\mathrm{PM}_{2.5}$, and a Partisol FRM Model 2000 air sampler operated by UDAQ for $\mathrm{PM}_{10}$, all of which were manufactured by Rupprecht and Patashnick (now Thermo Fisher Scientific, Waltham, Massachusetts). All filter samples collected by the writers were conditioned and weighed as previously discussed. Filter treatment by UDAQ were in accordance with established U.S. National Ambient Air Quality Standards (NAAQSs) monitoring protocols. Samples were collected over 23 or 24-h sample periods, with samplers arrayed to minimize horizontal and vertical spread while maintaining a minimum of 0.5 -m distance between samplers.

A $\mathrm{PM}_{2.5}$ comparison test was conducted in early March 2004 utilizing 15 MiniVol samplers and UDAQ's PM 2.5 FRM over 4 days. A $\mathrm{PM}_{10}$ comparison test was then conducted in late March 2004 over four sample periods with six MiniVols and the Anderson RAS PM 10 FRM. Samples were collected every 2 or 3 days to allow for filter deployment and collection. Another comparison study was carried out in July 2007 over 5 consecutive days. In this test, 20 MiniVol samplers were arranged adjacent to the UDAQ $\mathrm{PM}_{2.5}$ and $\mathrm{PM}_{10}$ FRMs. Three MiniVols sampled $\mathrm{PM}_{1}$, seven sampled $\mathrm{PM}_{2.5}$, seven sampled $\mathrm{PM}_{10}$, and three sampled TSP. The UDAQ FRMs had multiple filter cassettes with automated switching, allowing them to run nearly continuously. The MiniVols, however, required manual filter swapping between each sample. Therefore, the MiniVols sampled from 0:30 to 23:30, with the 1-h break to allow time to switch sample heads, record elapsed sample run time, and adjust sampler flows. Verified $\mathrm{PM}_{2.5}$ and $\mathrm{PM}_{10}$ values were obtained from UDAQ for all sample dates.

The accuracy and precision tests were carried out in the Cache Valley. Silva et al. (2007) showed that periods of elevated $\mathrm{PM}_{2.5}$ in Cache Valley in early 2004 were dominated by secondary particles, mostly $\mathrm{NH}_{4} \mathrm{NO}_{3},\left(\mathrm{NH}_{4}\right)_{2} \mathrm{SO}_{4}$, and organic carbon (OC), with $90 \%$ of the mass present in the submicron range. Cache Valley and other nearby mountain valleys experience episodic events of air pollution levels above NAAQS limits during winter due to a combination of topographical, meteorological, and source characteristics (Malek et al. 2006; Silva et al. 2007; Silcox et al. 2012; Lareau et al. 2013). Summertime elevated PM has typically occurred due to impacts from wildfire or windblown dust events.

\section{Results and Discussion}

\section{Field Study MCF Results}

Six field deployments have resulted in a total of 95 samples for comparison between reported OPC and MiniVol values for $\mathrm{PM}_{1}$, 380 for $\mathrm{PM}_{2.5}, 394$ for $\mathrm{PM}_{10}$, and 208 for TSP. Fig. 1 presents scatter plots of all the data, separated into the four size fractions. The $\mathrm{PM}_{k}$ was almost always greater than $V_{k}$ as few points are below the one-to-one line. Linear trends were evident in the $k=1 \mu \mathrm{m}$, $10 \mu \mathrm{m}$, and TSP graphs, with slopes between 1.2 and 1.6 and $0.78<R^{2}<0.82$. The linear fit to $k=2.5 \mu \mathrm{m}$ data had a slope of 1.4 but did not represent the data well $\left(R^{2}=0.06\right)$ due to a collection of low $V_{2.5}$ values $\left(<10 \mu \mathrm{m}^{3} \mathrm{~cm}^{-3}\right)$ paired with high $\mathrm{PM}_{2.5}$ concentrations $\left(>100 \mu \mathrm{g} \mathrm{m}^{-3}\right)$. The majority of the high $\mathrm{PM}_{2.5} /$ low $V_{2.5}$ pairings come from a single field study. The cause of these unusual values and their grouping is discussed at the end of this subsection. The $k=2.5 \mu \mathrm{m}$ values from the field study with multiple high $\mathrm{PM}_{2.5} /$ low $V_{2.5}$ pairings were removed and the remaining data were plotted in the graph inset [Fig. 1(b)]. The linear fit is significantly more representative $\left(R^{2}=0.66\right)$ with a slope of $2.4(n=279)$.

Chemical composition analyses were performed on select $\mathrm{PM}_{2.5}$ samples from two of the six datasets and on select $\mathrm{PM}_{2.5}$, $\mathrm{PM}_{10}$, and TSP filters from one dataset, all collected in the SJV. Water-soluble ions were quantified for all samples, while $\mathrm{OC}$ and elemental carbon (EC) were quantified in $\mathrm{PM}_{2.5}$ samples only based on the assumption that the majority of OC and EC were 

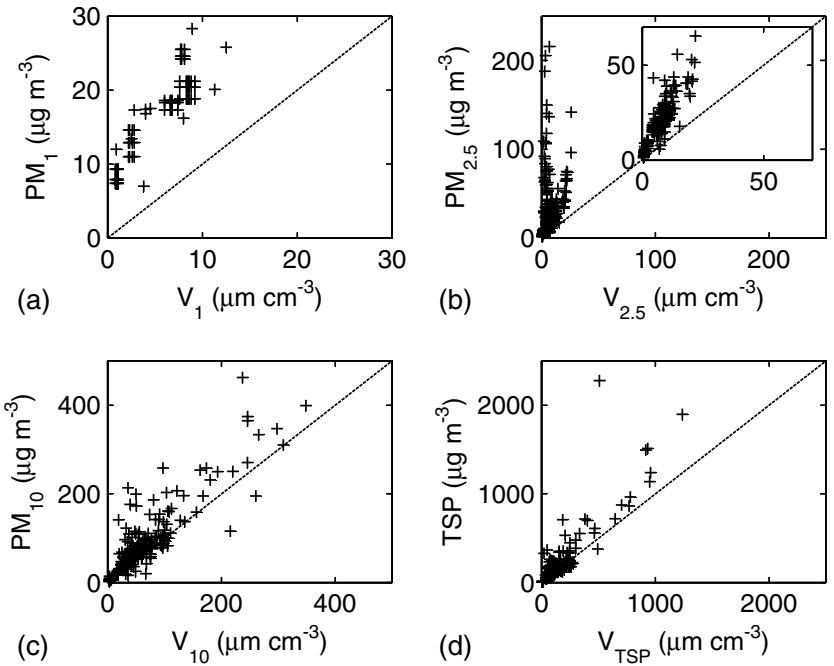

Fig. 1. Scatter plots of $V_{k}$ and $\mathrm{PM}_{k}$ for the following values of $k$ : (a) $1.0 \mu \mathrm{m}$; (b) $2.5 \mu \mathrm{m}$ (the inset shows the $V_{2.5} / \mathrm{PM}_{2.5}$ pairs after excluding data from one field study); (c) $10 \mu \mathrm{m}$; (d) TSP

present in the $\mathrm{PM}_{2.5}$ fraction. The results showed that most of the mass in analyzed samples (50-85\%) was composed of elements/ compounds not in the list of analytes. Malm and Hand (2007) used six particle composition classes to represent $\mathrm{PM}_{2.5}$ dry mass based on the Interagency Monitoring of Protected Visual Environments (IMPROVE) protocols; $\mathrm{NH}_{4} \mathrm{NO}_{3},\left(\mathrm{NH}_{4}\right)_{2} \mathrm{SO}_{4}, \mathrm{OC}, \mathrm{EC}$, crustal, and sea salt. As $\mathrm{NH}_{4} \mathrm{NO}_{3},\left(\mathrm{NH}_{4}\right)_{2} \mathrm{SO}_{4}$, and sea salt were quantified in the water-soluble ion test, the majority of PM during the research reported in this paper in the SJV was therefore assumed to be associated with crustal material. Particle chemical composition for the remaining three field studies is unknown.

A statistical summary of sample period average $\mathrm{MCF}_{k}$ values for all periods with more than two collocated comparisons is presented as a box and whisker plot (Fig. 2). As points of reference, the average density of soil is $2.65 \mathrm{~g} \mathrm{~cm}^{-3}$, the density of mercury is $13.5 \mathrm{~g} \mathrm{~cm}^{-3}$, and Peters (2006) provided several ambient PM density values derived from field studies that range from 1.77 to $2.64 \mathrm{~g} \mathrm{~cm}^{-3}$ (USDA 2007). The $y$-axis in Fig. 2 has been limited in order to show details at the lower values; one sample period had an average $\mathrm{MCF}_{2.5}$ of $23.5 \mathrm{~g} \mathrm{~cm}^{-3}$. Outliers are shown as plus signs and calculated as greater than (less than) the 75th (25th) percentile

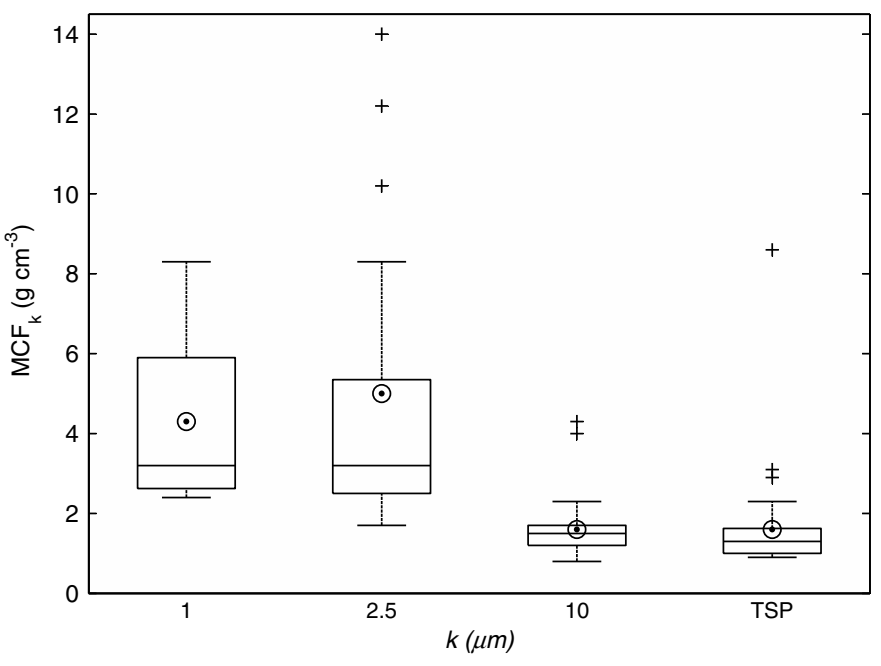

Fig. 2. Box and whisker plot of period averaged $\mathrm{MCF}_{k}$ values value plus (minus) $1.5 \times$ the interquartile range (IQR). The IQR is calculated as the difference between the 25 th and 75 th percentiles, which are shown by the top and bottom lines of the boxes. The whiskers extend to the most distant data values from the box edges within $1.5 \times$ the IQR. The $\mathrm{MCF}_{10}$ and $\mathrm{MCF}_{\mathrm{TSP}}$ values were more tightly grouped than the $\mathrm{MCF}_{1}$ and $\mathrm{MCF}_{2.5}$ values, as indicated by the smaller IQRs. This is also supported by the locations of the mean values for $\mathrm{MCF}_{10}$ and $\mathrm{MCF}_{\mathrm{TSP}}$, shown by the dots within circles, being much closer to the median, shown by the center line in the boxes. The overall mean \pm one SD and the median of the period average values, respectively, were as follows: (1) $\mathrm{MCF}_{1}=$ $4.3 \pm 2.2$ and $3.2 \mathrm{~g} \mathrm{~cm}^{-3}(n=5)$, (2) $\mathrm{MCF}_{2.5}=5.0 \pm 1.1$ and $3.2 \mathrm{~g} \mathrm{~cm}^{-3} \quad(n=36)$, (3) $\mathrm{MCF}_{10}=1.6 \pm 0.3$ and $1.5 \mathrm{~g} \mathrm{~cm}^{-3}$ $(n=38)$, and (4) $\mathrm{MCF}_{\mathrm{TSP}}=1.6 \pm 0.4$ and $1.3 \mathrm{~g} \mathrm{~cm}^{-3}(n=33)$. The absence of outliers for $\mathrm{MCF}_{1}$ is likely due the calculations being based on just five data points from a single field deployment.

The RSD between MCF values from different sample locations within a sample period averaged between 17 and $21 \%$ for $\mathrm{MCF}_{2.5}$, $\mathrm{MCF}_{10}$, and $\mathrm{MCF}_{\mathrm{TSP}}$, with maximum and minimum values for each size around 60 and 5\%, respectively. Samplers were spread around various facilities/operations for five studies. The sixth study was conducted as a part of the MiniVol precision and accuracy test in July 2007, and had lower variability than the others. Seven OPCs were deployed with 20 MiniVols, providing multiple pairwise collocated comparisons to determine the minimum variability of the calculated MCFs. The RSD averages were $10 \%$ for $\mathrm{MCF}_{1}, 8 \%$ for $\mathrm{MCF}_{2.5}$, and $5 \%$ for both $\mathrm{MCF}_{10}$ and $\mathrm{MCF}_{\mathrm{TSP}}$ with maximum values of $17,11,8$, and $6 \%$ for $\mathrm{MCF}_{1}, \mathrm{MCF}_{2.5}, \mathrm{MCF}_{10}$, and $\mathrm{MCF}_{\mathrm{TSP}}$, respectively. The data from all deployments show that calculated MCF values can be expected to have a minimum RSD of 5-10\%, an average RSD $\leq 25 \%$, and maximum RSDs can be $>50 \%$. High RSDs were found across the range of average MCF values and the amount of variability was different across size fractions within a sample period.

High individual MCF values were calculated during multiple field studies but were usually limited to the $\mathrm{MCF}_{2.5}$. Some factors potentially contributing to variations in $\mathrm{MCF}_{k}$ were discussed previously, including the properties of the particles, past and present environmental conditions, and sampling methodologies. Sample period average $\mathrm{MCF}_{k}$ values were graphically compared (not shown) with sample period average $T_{\mathrm{amb}}, \mathrm{RH}$, wind speed, and percent of OC, EC, ionic, and unknown chemical composition. Trends were not evident in any of these plots.

Sampling errors or irregularities may also influence the MCF. The majority of $\mathrm{MCF}_{2.5}$ values above $5 \mathrm{~g} \mathrm{~cm}^{-3}$, including the maximum of $66.1 \mathrm{~g} \mathrm{~cm}^{-3}$, were from the field study referenced previously with the high $\mathrm{PM}_{2.5} /$ low $V_{2.5}$ pairs. The cause of this grouping of high $\mathrm{MCF}_{2.5}$ values is unclear, although sampling irregularities are suspected. Meteorological conditions were hot and dry throughout, minimizing potential effects of water absorption by hygroscopic particles. There was not a significant $\mathrm{PM}_{2.5}$ composition difference between periods with higher and lower MCFs within this field study. $\mathrm{MCF}_{10}$ and $\mathrm{MCF}_{\mathrm{TSP}}$ patterns tended to be in accordance with $\mathrm{MCF}_{2.5}$, having correlation coefficients $(R)$ of 0.64 and 0.84 , respectively, but with much smaller changes in amplitude. Comparing MCF values with sample duration produced good negative correlations $(-0.69 \leq R \leq-0.64)$ for all $\mathrm{MCF}_{k}$, which means that $\mathrm{MCF}_{k}$ tended to increase as sample duration decreased. Contamination during filter handling and storage is a possible cause, one to which samples with smaller mass catch, i.e. samplers with $\mathrm{PM}_{2.5}$ impactor configurations and/or shorter sample times, would be more sensitive. Field and lab blanks, unfortunately, were not taken to monitor for and quantify contamination. Contamination mitigation and monitoring strategies have since been developed and successfully implemented. It is believed 
that a poor quality $\mathrm{PM}_{25}$ dataset resulted in the unusually high $\mathrm{MCF}_{2.5}$ values for a portion of this individual study.

The MCF method should be applied carefully and the quality of the data used in its calculation should be verified, as shown in the example discussed previously. In cases with poor quality data, the writers have occasionally chosen not to use the calculated MCF and instead used density values for the dominant particulate chemical component. In the example discussed previously, the average density of soil (2.65 $\mathrm{g} \mathrm{cm}^{-3}$; USDA 2007) replaced the calculated $\mathrm{MCF}_{2.5}$ values as measurements were being made of agricultural tillage plumes. If all the $\mathrm{MCF}_{k}$ values for this field study were removed, the mean \pm one SD and median values become $3.2 \pm 0.6$ and $2.7 \mathrm{~g} \mathrm{~cm}^{-3}$ for $\mathrm{MCF}_{2.5}(n=27), 1.4 \pm 0.3$ and $1.3 \mathrm{~g} \mathrm{~cm}^{-3}$ for $\mathrm{MCF}_{10}(n=28)$, and $1.1 \pm 0.2$ and $1.1 \mathrm{~g} \mathrm{~cm}^{-3}$ for $\mathrm{MCF}_{\mathrm{TSP}}$ $(n=21)$. The $\mathrm{MCF}_{1}$ statistics do not change as $\mathrm{PM}_{1}$ measurements were not made during that individual study.

\section{Application of the MCF}

Calculated $\mathrm{MCF}_{k}$ values have been used to convert $V_{k}$ data collected by multiple optical instruments into $\mathrm{PM}_{k}$. The MCFs were applied to OPC data, allowing the examination of temporal changes in mass loadings unresolved by filter-based MiniVols. For example, $\mathrm{PM}_{10}$ concentrations measured by a collocated MiniVol and OPC downwind of a commercial dairy over 2 days are shown (Fig. 3). The MiniVol collected integrated samples from 00:30 to 23:30 hrs. each day, yielding a single average concentration per sample period. The OPC provided a data point every $20 \mathrm{~s}$, which have been have averaged up to $5 \mathrm{~min}$ and $23 \mathrm{~h}$, corresponding to the MiniVol sample time, and multiplied by the average $\mathrm{MCF}_{10}$ for both days of $1.3 \mathrm{~g} \mathrm{~cm}^{-3}$. The diurnal $\mathrm{PM}_{10}$ patterns easily shown by the 5-min averaged OPC data are not evident in the 23-h average data that span the same time period. However, the influence of the evening peak is included in the 23-h average concentrations as they are higher than the OPC 5-min average levels throughout most of the sample period. Applying the MCF in this case allows for the analysis of $\mathrm{PM}_{10}$ at much smaller temporal scales, which may help to explain emissions patterns and lead to more effective and efficient mitigation strategies.

A main objective of most of the field deployments was to estimate PM emissions from a source. In all such cases, an emissions

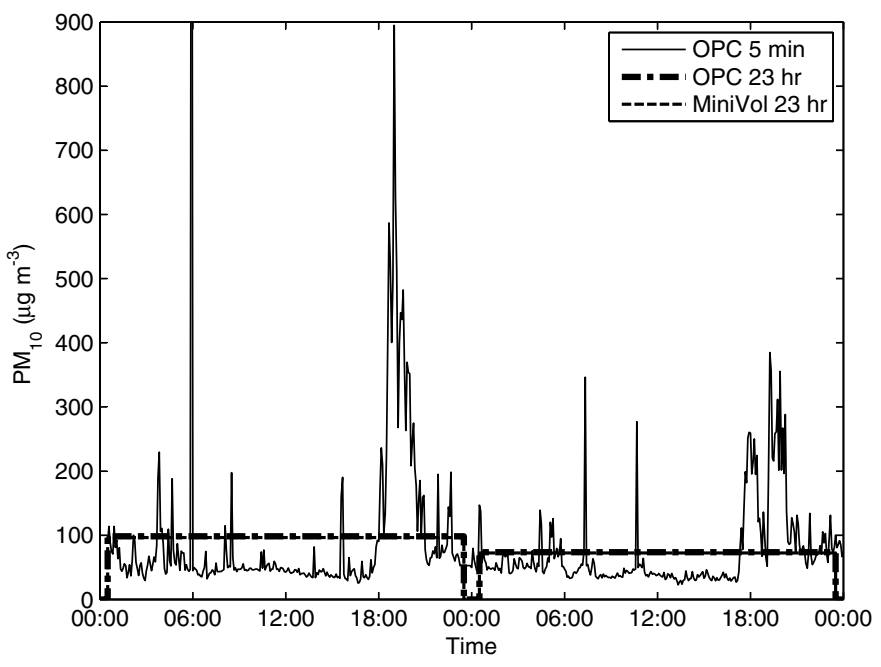

Fig. 3. Time series of $\mathrm{PM}_{10}$ concentrations measured immediately downwind of a dairy farm over 2 days as measured by a collocated MiniVol and OPC estimation methodology was employed that used the difference between downwind and upwind MiniVol concentrations. The OPC data may also be used for this after the conversion to mass concentration and on a finer temporal scale. For instance, Moore et al. (2011) estimated emissions during a wind erosion event based on $\mathrm{OPC} \mathrm{PM}_{k}$.

Another optical instrument to which the MCF has been applied is the Aglite elastic light detection and ranging (lidar) system, as described by Marchant et al. (2009). The Aglite lidar is a three wavelength system capable of scanning in both horizontal and vertical directions that measures laser pulse returns from particles in the atmosphere. The lidar data analysis algorithm, described by Zavyalov et al. (2009), utilizes OPC data collected during the lidar operation to calibrate the lidar return signal, with the final product being an estimate of $V_{k}$ in each lidar bin. The $\mathrm{MCF}_{k}$ values are then used to convert lidar $V_{k}$ to $\mathrm{PM}_{k}$ (Fig. 4).

Comparisons between MiniVol $\mathrm{PM}_{k}$ measurements and lidar and OPC data converted to $\mathrm{PM}_{k}$ with the $\mathrm{MCF}_{k}$ have been made in most of the field campaigns involving the lidar (Bingham et al. 2009; Zavyalov et al. 2009; Marchant et al. 2011; Moore et al. 2013). In summary, the results have shown good agreement between the three at upwind locations with more variability between the lidar and the other two point measurements downwind of sources, particularly nonstationary sources such as agricultural tillage operations. A large factor contributing to the observed differences is that the lidar is normally operated in a scanning mode and thereby collects coincident data at the downwind OPC and MiniVol location for only $5-10 \%$ of a given time period. The OPC $\mathrm{PM}_{k}$ values have usually been closer to MiniVol measurements due to collocation throughout the measurement period. For instance, the OPC 5-min average data (Fig. 3) were averaged over the 23-h MiniVol sample periods and plotted. The 23-h average OPC $\mathrm{PM}_{10}$ values are indistinguishable from the MiniVol reported concentrations, being only $2 \%$ higher. Refer to Moore et al. (2013) for more explanation of possible reasons for differences between the three measurements.

The SD of $\mathrm{PM}_{k}$ derived from $\mathrm{MCF}_{k}$ is calculated per Berthouex and Brown (2002)

$$
\begin{aligned}
\frac{\mathrm{SD}_{\mathrm{PM} k}^{2}}{\mathrm{PM}_{k}^{2}} & =\frac{\mathrm{SD}_{\mathrm{MCF} k}^{2}}{\mathrm{MCF}_{k}^{2}}+\frac{\mathrm{SD}_{V k}^{2}}{V_{k}^{2}} \text { or } \\
\left(\mathrm{RSD}_{\mathrm{PM} k}\right)^{2} & =\left(\mathrm{RSD}_{\mathrm{MCF} k}\right)^{2}+\left(\mathrm{RSD}_{V k}\right)^{2}
\end{aligned}
$$

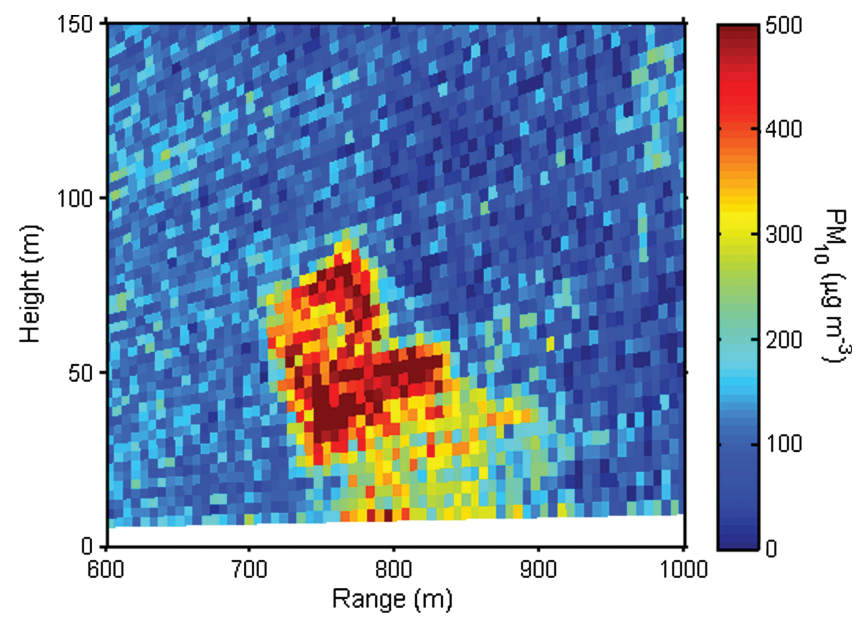

Fig. 4. (Color) Example of $\mathrm{PM}_{10}$ concentrations calculated from a single lidar scan through the use of the MCF; this vertical scan was taken along the downwind edge of an agricultural field being tilled 
In the case of the MCF datasets presented in this paper, the $\mathrm{RSD}_{\mathrm{PM} k}$ for the sample period average minimum $\mathrm{RSD}_{\mathrm{MCF} k}$ $(5 \%), \mathrm{RSD}_{\mathrm{MCF} k}$ for an arrayed deployment $(20 \%)$, and maximum $\mathrm{RSD}_{\mathrm{MCF}}(50 \%)$ were calculated as 21,28 , and $54 \%$, respectively, assuming a $\mathrm{RSD}_{V k}$ value of $20 \%$. If a $\mathrm{RSD}_{V k}$ value of $10 \%$ is used, the $\mathrm{RSD}_{\mathrm{PM} k}$ values drop to 11,22 , and $51 \%$, respectively.

Mass-calibrated lidar data have also been used to estimate source emissions through the application of a mass balance. Bingham et al. (2009) provide a description of the sampling and analysis methodology utilized to perform the mass-balance emission calculations. Several papers have estimated emissions based on this technique (Bingham et al. 2009; Marchant et al. 2011; Moore et al. 2011, 2013). A scanning, mass-calibrated lidar system such as this can provide PM concentration and emissions data over a large area in time steps on the order of seconds or minutes, allowing the identification of spatial inhomogeneity and temporal fluctuations and patterns, on horizontal and vertical extents not achievable through point measurements.

If researchers desire to use this $\mathrm{MCF}$ technique to provide a mass concentration calibration for optical systems, it is recommended that the reliability and reproducibility of the particle measurement systems be sufficiently characterized, particularly the optical systems. The writers use calibrations in concert with collocated tests in typical deployment conditions to accomplish this objective. The development and use of the $\mathrm{CCF}_{i j}$ has proven key in normalizing OPC count data to RSD values of $\leq 10 \%$; the variability in counts between the OPCs employed by the writers during a collocated test challenges the confidence in any one of them to provide the true absolute particle count. While this reduces the confidence in calculated $V$ and $V_{k}$, the $\mathrm{MCF}_{k}$ provides a stable point of reference for $\mathrm{PM}_{k}$. Additionally, the MCF should be applied with care as described previously.

\section{MiniVol Precision and Accuracy Test Results}

Collocated comparison tests between filter-based PM sensors were conducted in three separate studies, each with replicate MiniVol samplers over four to five sample periods. The $\mathrm{PM}_{2.5}$ concentrations measured by the FRM units ranged from 7.4 to $53.4 \mu \mathrm{g} \mathrm{m}^{-3}$, while $\mathrm{PM}_{10}$ levels ranged from 4.0 to $40.7 \mu \mathrm{g} \mathrm{m}^{-3}$. The maximum and minimum $\mathrm{PM}_{10}$ concentrations being lower than the $\mathrm{PM}_{2.5}$ values are not of concern; all but one of the $\mathrm{PM}_{10}$ comparison tests were conducted on separate days from the $\mathrm{PM}_{2.5}$ tests and, in the case of the coincident test, the reported $\mathrm{PM}_{10}$ level was higher than the $\mathrm{PM}_{2.5}$ level. All data were screened for noted sample handling and collection errors.

Fig. 5 presents both $\mathrm{PM}_{2.5}$ and $\mathrm{PM}_{10}$ comparisons with the MiniVol data along the $x$-axis and the FRM data along the $y$-axis. Most of the MiniVol data are fairly well clustered, with most cluster cores within $\pm 10 \%$ of the one-to-one line across the range of observed values (Fig. 5). However, there are several points significantly outside of the clusters. The extreme value test was used to determine if these points were statistical outliers. Nineteen points were statistical outliers and have been marked on Fig. 5 by a dot inside the marker. All but two of the outliers were found in the $\mathrm{PM}_{2.5}$ dataset, and 12 of those were in the $\mathrm{PM}_{2.5}$ comparison test carried out in March 2004. Out of the four sample periods in this single collocated test, one sampler contributed four statistical outliers, a second contributed three outliers, and a third contributed two outliers. Multiple outliers resulting from a single sampler is suggestive of sampler operational issues. Therefore, all data from these samplers were removed from further analysis and the outlier analysis for this $\mathrm{PM}_{2.5}$ dataset was performed again, resulting in only three identified as statistical outliers for a total

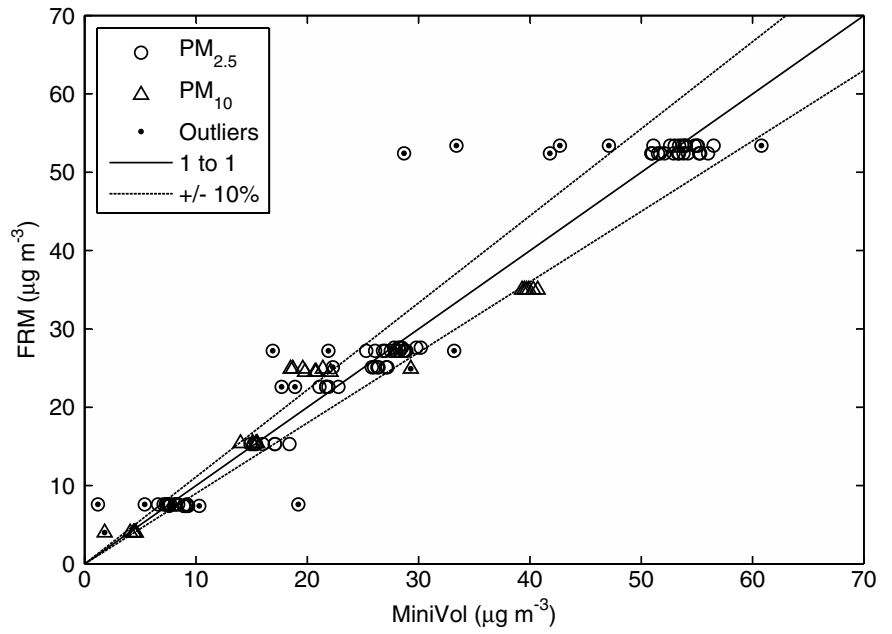

Fig. 5. Comparison of $\mathrm{PM}_{2.5}$ and $\mathrm{PM}_{10}$ concentrations reported by the MiniVols and the respective FRM samplers

of 10 from all datasets. All other samplers with outlier data points had just one each. The subsequent linear regression equations were developed based on the remaining points; $F R M=0.99 \times$ MiniVol $+0.31, \quad R^{2}=0.962$, for $\mathrm{PM}_{2.5} ;$ and $\mathrm{FRM}=0.83 \times$ MiniVol $+3.90, R^{2}=0.918$, for $\mathrm{PM}_{10}$.

Potential causes of variability and outliers between the MiniVol samples may include, but not limited to, the following: (1) recording errors during weighing or operation logging, (2) improper setting of the sample flow, (3) sample contamination, (4) improper assembly of the sampler head, (5) nonuniform PM levels across the inlets, and (6) random variability in sampler operation and mass catch determination. Preventative measures were taken to decrease the likelihood of the first five listed causes. Personnel were trained on proper instrument assembly, instrument operation, sample handling, filter weighing, and data logging procedures to minimize human error. Filter exposure during handling and transport was minimized to prevent contamination. Samplers were deployed close together, in the ambient air, and within areas of uniform surface and source conditions to maximize uniformity in average PM concentrations. Random variability in sampler operation would likely result in relatively small variations in reported concentrations, not the large differences seen in the case of some outliers. The outliers seen in the research reported in this paper and not removed due to sampler operational issues, as previously discussed, are likely the result of a combination of human error, instrument operation anomalies, or random variations in PM concentration, although the exact cause(s) were not identifiable. Unless otherwise noted, these data were not excluded from further calculations due to the lack of an identified cause.

Table 2 lists various statistical measures of the variability between the MiniVol samplers for each size fraction in each study. The variability of reported PM concentrations between the MiniVols within a sample period, expressed as the RSD, ranged from 1 to $27 \%$. The variability between MiniVols was generally smaller across all size ranges during the year 2007 study compared to the year 2004 studies with all average RSDs below 10\%. The bias of the MiniVols was calculated by subtracting the sample period FRM concentration from the average MiniVol concentration and averaging across the sample periods within each study. The average $\mathrm{PM}_{2.5}$ biases were less than $\pm 1 \mu \mathrm{g} \mathrm{m}^{-3}$, but the $\mathrm{PM}_{10}$ biases averaged $-1.9 \mu \mathrm{g} \mathrm{m}^{-3}$ during the March 2004 study 
Table 2. Statistical Measures of the Intrainstrument and Interinstrument Comparability Test Datasets, Including Outliers, Conducted in March 2004 and July 2007

\begin{tabular}{|c|c|c|c|c|c|c|c|}
\hline \multirow[b]{2}{*}{ Statistic } & \multirow[b]{2}{*}{ Units } & \multicolumn{2}{|c|}{ March 2004} & \multicolumn{4}{|c|}{ July 2007} \\
\hline & & $\mathrm{PM}_{2.5}$ & $\mathrm{PM}_{10}$ & $\mathrm{PM}_{1}$ & $\mathrm{PM}_{2.5}$ & $\mathrm{PM}_{10}$ & $\mathrm{TSP}^{\mathrm{a}}$ \\
\hline Sample periods & Count & \multicolumn{2}{|c|}{4} & \multicolumn{4}{|c|}{5} \\
\hline \multicolumn{8}{|c|}{$\begin{array}{l}\text { Federal reference method PM concentration } \\
\text { Range }\end{array}$} \\
\hline Minimum & $\mu \mathrm{g} \mathrm{m}^{-3}$ & 7.6 & 4.0 & - & 7.4 & $35.0^{\mathrm{b}}$ & - \\
\hline Maximum & $\mu \mathrm{g} \mathrm{m}^{-3}$ & 53.4 & 24.9 & - & 27.6 & 一 & - \\
\hline \multicolumn{8}{|c|}{ MiniVol PM concentration } \\
\hline \multicolumn{8}{|l|}{ Range } \\
\hline Minimum & $\mu \mathrm{g} \mathrm{m}^{-3}$ & 6.6 & 1.8 & 7.4 & 7.6 & 17.9 & 45.3 \\
\hline Maximum & $\mu \mathrm{g} \mathrm{m}^{-3}$ & 56.5 & 29.3 & 25.5 & 30.2 & 49.5 & 78.8 \\
\hline \multicolumn{8}{|l|}{ Relative SD } \\
\hline Average & Percent & 10 & 13 & 8 & 7 & 4 & 3 \\
\hline Minimum & Percent & 5 & 4 & 3 & 3 & 1 & 3 \\
\hline Maximum & Percent & 14 & 27 & 14 & 10 & 8 & 3 \\
\hline \multicolumn{8}{|l|}{ Bias } \\
\hline Average & $\mu \mathrm{g} \mathrm{m}^{-3}$ & -0.5 & -1.9 & - & +0.6 & $+4.9^{\mathrm{b}}$ & 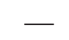 \\
\hline SD & $\mu \mathrm{g} \mathrm{m}^{-3}$ & 0.7 & 1.9 & - & 1.4 & - & - \\
\hline Samples & Count & 48 & 18 & 15 & 33 & 33 & 12 \\
\hline Outliers & Count & 3 & 2 & 0 & 5 & 0 & 0 \\
\hline \multicolumn{8}{|c|}{ Federal reference method/MiniVol ratio } \\
\hline Average & Unitless & 1.03 & 1.15 & - & 0.96 & 0.88 & - \\
\hline SD & Unitless & 0.16 & 0.31 & - & 0.11 & 0.01 & - \\
\hline $95 \% \mathrm{CI}$ & Unitless & 0.04 & 0.14 & - & 0.04 & 0.01 & - \\
\hline
\end{tabular}

Note: - indicates no data or insufficient data.

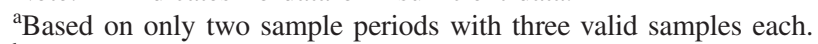

${ }^{\mathrm{b}}$ Only one $\mathrm{PM}_{10}$ sample collected by the FRM sampler.

and $+4.9 \mu \mathrm{g} \mathrm{m}^{-3}$ for the single $\mathrm{PM}_{10}$ sample period in the July 2007 study with a corresponding FRM sample.

The results of the FRM and MiniVol comparison from these collocated sample periods are presented (Table 2) as a ratio. An FRM/ MiniVol ratio of 1.0 shows the MiniVol reported the same PM concentration as the FRM, while a ratio greater than 1.0 results from lower MiniVol concentrations and vice versa for ratios less than 1.0. The average ratios from the two $\mathrm{PM}_{2.5}$ tests \pm the $95 \%$ confidence interval $(\mathrm{CI})$ were $1.03 \pm 0.04$ and $0.96 \pm 0.04$ for the year 2004 and 2007 studies, respectively. These show the MiniVols were, on average, in very good agreement with the $\mathrm{PM}_{2.5}$ FRM under these conditions, even that the $95 \%$ CIs bound the value 1.00 in both cases. The $\mathrm{PM}_{10}$ ratios showed a higher deviation from 1.00 with $1.15 \pm 0.14$ and $0.88 \pm 0.01$ for the two studies, although the average values are still within $15 \%$ of 1.00 .

Several previous MiniVol precision and accuracy studies have been reported in multiple PM sampling configurations. Heal et al. (2000), Baldauf et al. (2001), and Chen et al. (2007) reported very good MiniVol precision. Baldauf et al. (2001), Chow et al. (2002), and Chen et al. (2011) found the MiniVols yielded PM levels very similar to the comparison sampling systems. Hill et al. (1999) found that the $\mathrm{PM}_{2.5}$ MiniVol was statistically equivalent to an FRM only when results were field blank corrected. Chow et al. (2006) found differences between PM $_{2.5}$ MiniVols and FRMs at multiple sites ranging from 1.23 to 1.41 and had an overall average of 1.32. Heal et al. (2000) reported the MiniVol correlated very well with a FRM $\mathrm{PM}_{10}$ sampler in indoor environments with $\mathrm{PM}_{10}$ levels $\sim 10 \mu \mathrm{g} \mathrm{m}^{-3}$, but on average reported mass concentrations $23 \%$ greater. Salter and Parsons (1999) found a MiniVol did not correlate well in comparisons with a tapered element oscillating microbalance (TEOM; Rupprecht and Patashnick, now Thermo Fisher Scientific, Waltham, Massachusetts) and a Partisol. Kingham et al. (2006) found weak $\mathrm{PM}_{10}$ correlations with data from both a TEOM and a DustTrak during one series of measurements and good correlations during a second series of measurements.

Insights gained through these tests and analyses with respect to obtaining accurate and precise PM measurements with MiniVols (or any other PM system) should be noted. First, proper maintenance and regular inspection of the MiniVol is required, with particular focus on flow calibration and the impactor assembly. Second, occasional collocated tests are suggested for comparisons between multiple MiniVols and, if possible, an FRM to monitor for operational issues. If possible, these tests should be carried out under conditions typical of deployments. Third, proper personnel training is key to reducing human error.

\section{Summary and Conclusions}

Currently available PM monitoring systems based on optical measurements generally use calibration factors calculated from historical data to estimate PM concentrations. However, the applicability of these calibrations may be questionable when properties of the measured aerosol are different from properties of the aerosols used to estimate the calibration factor. In this paper a simple, onsite procedure to determine the $\mathrm{MCF}_{k}$ has been presented that may be used to convert data from an optical instrument into $\mathrm{PM}_{k}$ levels based on the actual measurement conditions. This procedure may also be used with an optical system for which a PM calibration has not been developed. Data from field measurements have been presented to demonstrate typical $\mathrm{MCF}_{k}$ values for $k=1 \mu \mathrm{m}, 2.5 \mu \mathrm{m}$, $10 \mu \mathrm{m}$, and TSP. The $\mathrm{MCF}_{1}$ and $\mathrm{MCF}_{2.5}$ values tend to be higher than $\mathrm{MCF}_{10}$ and $\mathrm{MCF}_{\mathrm{TSP}}$ within a sample period. The average RSDs were about $20 \%$ for arrayed measurements made during multiple field studies and $<10 \%$ for collocated measurements. The $\mathrm{MCF}_{k}$ has been key in converting optical instrument data to mass concentration, which has allowed for examination of concentration and emissions data on much smaller time scales and, in the case of a scanning lidar, over much greater spatial scales.

Results from studies examining the precision and accuracy of the MiniVol PM sampler are given. The sample period RSDs were usually $<10 \%$ for $\mathrm{PM}_{1}, \mathrm{PM}_{2.5}, \mathrm{PM}_{10}$, and TSP size fractions. Comparisons at the $\mathrm{PM}_{2.5}$ size fraction between MiniVols and FRMs showed excellent agreement with average FRM/MiniVol ratios $\pm 95 \% \mathrm{CI}$ of $1.03 \pm 0.04$ and $0.96 \pm 0.04$ and average biases $< \pm 1 \mu \mathrm{g} \mathrm{m}^{-3}$. Results of the $\mathrm{PM}_{10}$ comparisons were not as strong with average ratios of $1.15 \pm 0.14$ and $0.88 \pm 0.01$, and biases of $-1.9 \mu \mathrm{g} \mathrm{m}^{-3}$ and $+4.9 \mu \mathrm{g} \mathrm{m}^{-3}$. In conclusion, the MiniVols yielded $\mathrm{PM}_{2.5}$ values that were essentially equivalent to $\mathrm{PM}_{2.5}$ concentrations reported by FRM samplers under these test conditions and $\mathrm{PM}_{10}$ values were in good agreement with $\mathrm{PM}_{10}$ FRM measurements.

\section{Acknowledgments}

The research reported in this paper is partially based upon work supported by the USDA, Cooperative Agreement No. 58-36259-743. Any opinions, findings, conclusions, or recommendations expressed in this paper are those of the writers and do not necessarily reflect the view of the USDA. The State of Utah, Department of Environmental Quality, also provided funding and equipment support for some of the data collection. The writers thank the teams involved in conducting the field work. Mention of a trademark, proprietary product, or vendor is for information purposes only and does not constitute an endorsement by the USDA, State of Utah, Utah State University, or Space Dynamics Laboratory. 


\section{References}

Baldauf, R. W., Lane, D. D., Marotz, G. A., and Wiener, R. W. (2001). "Performance evaluation of the portable MiniVOL particulate matter sampler." Atmos. Environ., 35(35), 6087-6091.

Berthouex, P. M., and Brown, L. C. (2002). "Precision of calculated values." Statistics for environmental engineers, 2nd Ed., Lewis Publishers, Boca Raton, FL, 87-95.

Bingham, G. E., et al. (2009). "Lidar based emissions measurement at the whole facility scale: Method and error analysis." J. Appl. Rem. Sens., 3(1), 033510

Binnig, J., Meyer, J., and Kasper, G. (2007). "Calibration of an optical particle counter to provide PM2.5 mass for well-defined particle materials." J. Aerosol Sci., 38(3), 325-332.

Chen, F.-L., et al. (2007). "Course particulate matter concentrations from residential outdoor sites associated with the North Carolina asthma and children's environment studies (NC-ACES)." Atmos. Environ., 41(6), 1200-1208.

Chen, F.-L., et al. (2011). "Field evaluation of portable and central site PM samplers emphasizing additive and differential mass concentration estimates." Atmos. Environ., 45(26), 4522-4527.

Chow, J. C., et al. (2006). "PM2.5 and PM10 mass measurements in California's San Joaquin Valley." Aerosol Sci. Technol., 40(10), 796-810.

Chow, J. C., Watson, J. G., Edgerton, S. A., Vega, E., and Ortiz, E. (2002). "Spatial differences in outdoor PM10 mass and aerosol composition in Mexico City.” J. Air Waste Manage. Assoc., 52(4), 423-434.

Finlayson-Pitts, B. J., and Pitts, J. N., Jr. (1999). Chemistry of the upper and lower atmosphere: Theory, experiments, and applications, Academic, San Diego.

Grimm, H., and Eatough, D. J. (2009). "Aerosol measurement: The use of optical light scattering for the determination of particulate size distribution, and particulate mass, including the semi-volatile fraction." J. Air Waste Manage. Assoc., 59(1), 101-107.

Heal, M. R., Beverland, I. J., McCabe, M., Hepburn, W., and Agius, R. M. (2000). "Intercomparison of five PM10 monitoring devices and the implications for exposure measurement in epidemiological research." J. Environ. Monit., 2(5), 455-461.

Held, T., Ying, Q., Kaduwela, A., and Kleeman, M. (2004). "Modeling particulate matter in the San Joaquin Valley with a source-oriented externally mixed three-dimensional photochemical grid model." Atmos. Environ., 38(22), 3689-3711.

Hill, J. S., Patel, P. D., and Turner, J. R. (1999). "Performance characterization of the MiniVol PM2.5 sampler." Proc., Air and Waste Management AssociationAnnual Meeting, Pittsburgh.

Kingham, S., Durand, M., Aberkane, T., Harrison, J., Wilson, J. G., and Epton, M. (2006). "Winter comparison of TEOM, MiniVol and DustTrak PM10 monitors in a woodsmoke environment." Atmos. Environ., 40(2), 338-347.

Lareau, N. P., et al. (2013). "The persistent cold-air pool study." Bull. Am. Meteorol. Soc., 94(1), 51-63.
Malek, E., Davis, T., Martin, R. S., and Silva, P. J. (2006). "Meteorological and environmental aspects of one of the worst national air pollution episodes (January, 2004) in Logan, Cache Valley, Utah, USA." Atmos. Res., 79(2), 108-122.

Malm, W. C., and Hand, J. L. (2007). "An examination of the physical and optical properties of aerosols collected in the IMPROVE program.' Atmos. Environ., 41(16), 3407-3427.

Malm, W. C., Schichtel, B. A., Pitchford, M. L., Ashbaugh, L. L., and Eldred, R. A. (2004). "Spatial and monthly trends in speciated fine particle concentration in the United States." J. Geophys. Res., 109(D3), D03306.

Marchant, C. C., et al. (2009). "Aglite lidar: A portable elastic lidar system for investigating aerosol and wind motions at or around agricultural production facilities." J. Appl. Rem. Sens., 3(1), 033511.

Marchant, C. C., et al. (2011). "Estimation of dairy particulate matter emission rates by lidar and inverse modeling." Trans. ASABE, 54(4), $1453-1463$.

Moore, K. D., et al. (2011). "Comparisons of measurements and predictions of PM concentrations and emission rates from a wind erosion event." Proc., Int. Symp. on Erosion and Landscape Evolution, American Society of Agricultural and Biological Engineers, St. Joseph, MI.

Moore, K. D., et al. (2013). "Particulate emissions calculations from fall tillage operations using point and remote sensors." J. Environ. Qual., 42(4), 1029-1038.

Peters, T. M. (2006). "Use of the aerodynamic particle sizer to measure ambient PM10-2.5: The coarse fraction of PM10." J. Air Waste Manage. Assoc., 56(4), 411-416.

Salter, L. F., and Parsons, B. (1999). "Field trials of the TEOM and Partisol for PM10 monitoring in the St. Austell china clay area, Cornwall, UK." Atmos. Environ., 33(13), 2111-2114.

Schmid, O., Karg, E., Hagen, D. E., Whitefield, P. D., and Ferron, G. A. (2007). "On the effective density of non-spherical particles as derived from combined measurements of aerodynamic and mobility equivalent size." J. Aerosol Sci., 38(4), 431-443.

Silcox, G. D., Kelly, K. E., Crosman, E. T., Whiteman, C. D., and Allen, B. L. (2012). "Wintertime PM2.5 concentrations during persistent, multi-day cold-air pools in a mountain valley." Atmos. Environ., 46, 17-24.

Silva, P. J., Vawdrey, E. L., Corbett, M., and Erupe, M. (2007). "Fine particle concentrations and composition during wintertime inversions in Logan, Utah, USA.” Atmos. Environ., 41(26), 5410-5422.

Tropp, R., Jones, K., Kuhn, G., and Berg, N. (1998). "Comparison of PM2.5 saturation samplers with prototype PM2.5 federal reference method samplers." Proc., Air and Waste Management Association Annual Meeting, Pittsburgh.

USDA. (2007). "National soil survey handbook." 〈http://soils.usda.gov/ technical/handbook/> (Dec. 20, 2007).

Zavyalov, V. V., et al. (2009). "Aglite lidar: Calibration and retrievals of well characterized aerosols from agricultural operations using a threewavelength elastic lidar." J. Appl. Rem. Sens., 3(1), 033522. 